
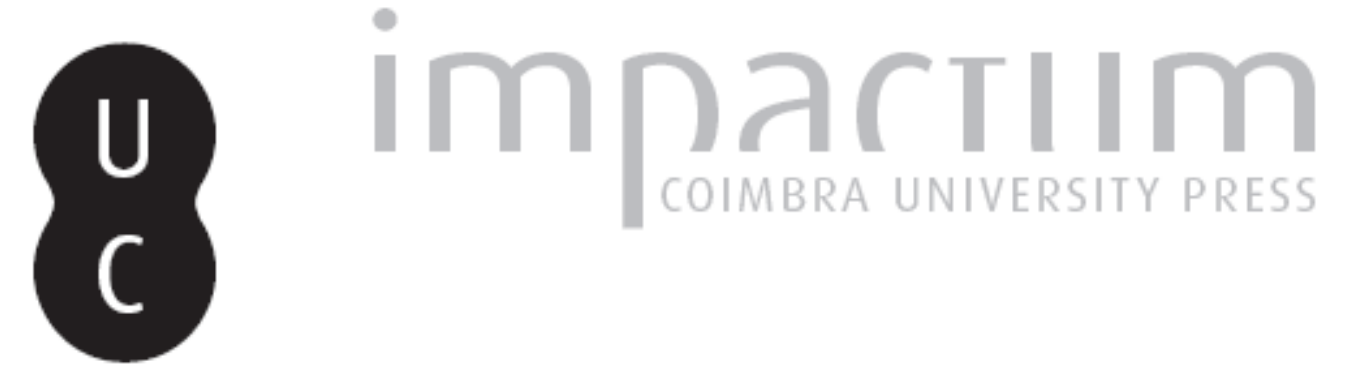

[Recensão a] J.-F. Labourdette, Le Portugal de 1780 à 1802

Autor(es): D'Araújo, Ana Cristina Bartolomeu

Publicado por: Imprensa da Universidade de Coimbra

URL persistente:

URI:http://hdl.handle.net/10316.2/45349

DOI:

DOI:https://doi.org/10.14195/2183-8925_9-3_23

Accessed : $\quad$ 26-Apr-2023 15:09:54

A navegação consulta e descarregamento dos títulos inseridos nas Bibliotecas Digitais UC Digitalis, UC Pombalina e UC Impactum, pressupõem a aceitação plena e sem reservas dos Termos e Condições de Uso destas Bibliotecas Digitais, disponíveis em https://digitalis.uc.pt/pt-pt/termos.

Conforme exposto nos referidos Termos e Condições de Uso, o descarregamento de títulos de acesso restrito requer uma licença válida de autorização devendo o utilizador aceder ao(s) documento(s) a partir de um endereço de IP da instituição detentora da supramencionada licença.

Ao utilizador é apenas permitido o descarregamento para uso pessoal, pelo que o emprego do(s) título(s) descarregado(s) para outro fim, designadamente comercial, carece de autorização do respetivo autor ou editor da obra.

Na medida em que todas as obras da UC Digitalis se encontram protegidas pelo Código do Direito de Autor e Direitos Conexos e demais legislação aplicável, toda a cópia, parcial ou total, deste documento, nos casos em que é legalmente admitida, deverá conter ou fazer-se acompanhar por este aviso. 


\section{REVISTA DE HISTÓRIA DAS IDEIAS 9}

\section{O SAGRADO E O PROFANO ***}

HOMENAGEM A J. S. DA SILVA DIAS

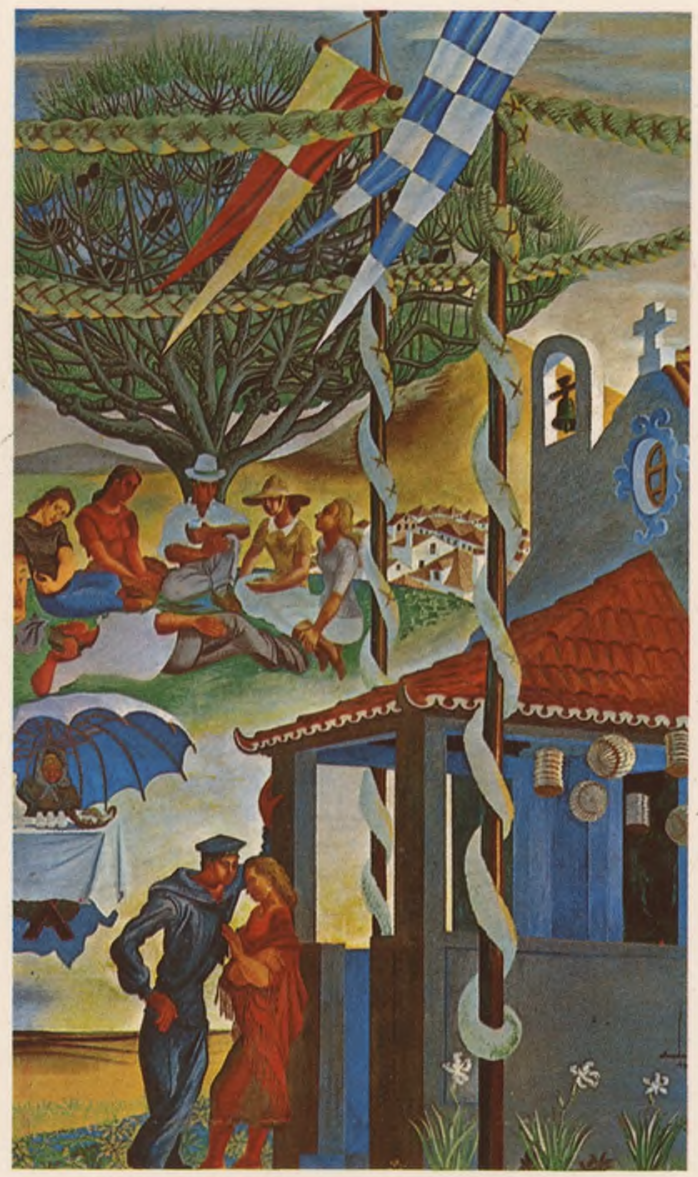

INSTITUTO DE HISTÓRIA E TEORIA DAS IDEIAS FACULDADE DE LETRAS 


\section{Recensões}

dos elos fortes nas relações entre o poder temporal e espiritual em Espanha. Favorito de Godoy, favorito igualmente do monarca intruso D. José Napoleão I acabaria, ao contrário de Aranza, Felix Amat, O’Farril, Llórente, Suarez de Santander e outros, por nunca sentir a necessidade de refutar a sua conduta passada, acomodando-se ao exílio em Paris.

Mais complexo se afigura o envolvimento político de D. Felix Amat, arcebispo titular de Palmira e abade da Granja, depois da abdicação de Fernando VII. Segundo Huiguerela del Piño, Amat permanece como «una de las personalidades eclesiásticas más interessantes de su época porque será de los pocos que adopten una actitud responsable ante las grandes incitaciones ideológicas que se presentaron al clero español de finales del siglo XVIII e principios del XIX, como que el jansenismo, la Ilustración y el liberalismo».

$\mathrm{O}$ confronto da trajectória político-cultural de Amat com o colaboracionismo linear e ocasional do cónego de Segóvia, D. Vincent Ramon Gomes, permite, sem margem para dúvidas, distinguir e distanciar o caso atípico e excepcional do fenómeno mais corrente de colaboracionismo no clero regular e secular.

No termo deste percurso de leitura de um trabalho colectivo que, estando ainda nas margens da prosopografia, abre interessantes e ricas perspectivas de confronto e reflexão, a nossa memoria arrasta-nos inevitavelmente, para a evocação de situações de afrancesamento no clero portugués, onde se denotam sensíveis pontos de contacto com alguns processos mencionados. Ocorrem-nos, por exemplo, os casos do Bispo -do Porto, D. Antonio de S. José e Castro, do Inquisidor Geral, D. José Maria de Melo e do Cardeal Patriarca de Lisboa, D. José Francisco Miguel Antonio de Mendonça.

Trabalhos como este, poderão constituir um bom estímulo para um estudo em profundidade, que há tanto tarda.

\section{Ana Cristina Bartolomeu (ïAraújo}

J.-F. Labourdette, Le Portugal de 1780 à 1802, Paris, SEDES, Col. Regards sur FHistoire, 1985, 178 pp.

Foram recentemente publicados na Colecção Regards sur FHistoire (SEDES) e sob a direcção de André Corvisier, três títulos que têm em comum a análise do mesmo período para Espanha, Portugal e Itália. Estão por conseguinte, a par desta obra as de Ph. Loupés e J. Georgelin respectivamente, 


\section{Revista de Historia das Ideias}

L'Espagne de 1780 à 1802, e L'Italie à la fin du XVIIIe siècle (vers 1780-1802). Esta criteriosa sucessão de publicações, pela qualidade dos textos apresentados, possibilita uma sintética e rica visão de conjunto da fase final do Antigo Regime numa mancha importante da Europa meridional.

A obra de Labourdette foi elaborada, como nos diz o Autor, para responder às exigências do programa de agregação em História (Universidade de Angers). Trata-se pois de um texto não muito desenvolvido mas onde a clareza e o rigor são constantes.

Distribuída por três partes, para além de uma Introdução e uma Conclusão, a obra trata genericamente os temas: «Estado e Sociedade»; «A Economia Portuguesa»; e «Portugal perante a Revolução Francesa».

A introdução é sempre uma abertura a um texto a desenvolver. Neste caso, e compreensivelmente, não é isso que acontece. Numa obra que tem como principal destinatário o leitor estrangeiro, o Autor preferiu esclarecer os prolongamentos do território nos seus três grandes conjuntos geográfícos em relação à Peninsula e o sentido histórico da constituição do Estado Português, seguindo naturalmente a lição de Orlando Ribeiro mas sem qualquer referência à obra de José Mattoso.

A escassez de trabalhos publicados no domínio da demografia histórica em Portugal - facto devidamente assinalado por Labourdette - justificou, por certo, o tratamento também preliminar do comportamento da população ao longo do século XVIII. Se os censos gerais de 1798 e particularmente o de 1801-1802 permitem, embora sujeitos a correcção, estimativas aceitáveis - como o demonstrou Fernando de Sousa já os números apresentados em 1736 por D. Luís Caetano de Lima são incertos e imprecisos. Apesar da precaridade deste termo de comparação, o Autor regista uma percentagem de aumento da população de cerca de $43 \%$, bastante próxima portanto, da de outros países da Europa no mesmo período.

$\mathrm{Na}$ primeira parte Labourdette caracteriza sumariamente a sociedade e o Estado articulando no seu discurso fundamentalmente as contribuições de Victorino Magalhães Godinho, Estrutura da Antiga Sociedade Portuguesa e Antonio Manuel Hespanha, Historia das Instituições. Época Medieval e Moderna.

Analisa o Pombalismo numa perspectiva socio-económica, começando por apreciar o seu significado político. Ao progredir para o que intitula «a emergência de um novo ideal 
social: o burguês capitalista», o Autor parece dar um peso excessivo a uma burguesia, cuja existência é indiscutível, mas que permanece mal conhecida. Bastaria ter presente as trajectórias de famílias como os Bandeiras e os Quinielas para desaconselhar tão rígida classificação, já que, nestes casos, é hoje geralmente aceite uma linha de continuidade entre burguesia pombalina, nobreza mariana e fidalguia liberal.

$\mathrm{Na}$ segunda parte o Autor explora a ligação de Portugal Atlântico com a Inglaterra, numa perspectiva de coincidência de interesses económicos, acentuando o crescimento sincopado e gradual do mercado interno e externo português ao longo do século XVIII. A propósito, revela ter em preparação um estudo sobre o comércio franco-português, do qual já utiliza nesta obra dois quadros para os anos que medeiam entre 1770 e 1789, elaborados a partir de documentação inédita do ministério francês de Negócios Estrangeiros.

Por fim o Autor assinala de forma precária alguns contributos e indicadores de mutação cultural e ideológica que precedem a Revolução de 1820, deixando em aberto questões como: a diversidade de influências no Iluminismo português; linhas de intercepção e descontinuidade entre as Luzes Pombalinas e as Luzes Marianas; e modalidades e processos de constituição de uma corrente de opinião favorável aos acontecimentos revolucionários de 1789. Pensamos pois que este capítulo, pela complexidade dos temas abarcados, merecia um tratamento mais desenvolvido e detalhado.

E já agora um reparo de ordem formal: num trabalho de divulgação como este seria aconselhável que, em vez de uma breve orientação bibliográfica, o leitor pudesse dispor de uma bibliografia exaustiva e de uma cronologia comparada.

Ao concluirmos a leitura deste sugestivo trabalho somos levados a pensar no grande interesse e curiosidade que a história portuguesa continua a desfrutar no estrangeiro, apesar da pouca divulgação, ou mesmo da ausência de traduções em língua francesa e inglesa, dos mais recentes trabalhos da nossa historiografia.

Ana Cristina Bartolomeu d'Araújo 